\title{
Syntheses and Conformational Studies of Poly(S-aminoalkyl-homocysteine)s and Their Benzyloxycarbonyl Derivatives
}

\author{
Tadao Hayakawa, Yoshiyuki Kondo, and Nagao Kobayashi \\ Institute of High Polymer Research, Faculty of Textile Science and Technology, \\ Shinshu University, Ueda, Japan.
}

(Received March 31, 1975)

\begin{abstract}
Poly}(S$-2-benzyloxycarbonylaminoethyl-L-homocysteine), poly( $S$-3-benzyloxycarbonylaminopropyl-L-homocysteine), $\operatorname{poly}(S$-L-2-benzyloxycarbonylaminopropyl-Lhomocysteine), and poly(S-L-2-benzyloxycarbonylaminopropyl-D-homocysteine) were prepared by the NCA method. The protected polymers were converted into $\operatorname{poly}(S$-2-aminoethyl-L-homocysteine), poly(S-3-aminopropyl-L-homocysteine), poly( $S$-L-2-aminopropyl-Lhomocysteine), and $\operatorname{poly}(S$-L-2-aminopropyl-D-homocysteine) through decarbobenzoxylation with hydrogen bromide. The conformation of these polypeptides was studied by means of their infrared(IR) spectra, optical rotatory dispersions(ORD), and circular dichroisms $(\mathrm{CD})$. From the IR measurements all polymers were found to be in the $\alpha$ helix in the solid state. The results of the ORD and CD suggest that these protected polymers take an $\alpha$-helix conformation in chloroform and a random coil conformation in DCA. In a chloroform-DCA mixture, the helix-coil transition of these polymers was observed at $60-80-\%$ DCA. The ORD and CD curves of the deprotected polymers showed that the polymers took a random coil in the $\mathrm{pH}$ range below 7 . However, when the $\mathrm{pH}$ is increased above 7 , the spectra gradually change into the $\alpha$-helix. Moreover, the helix-coil transition of the polypeptide occurs at a lower $\mathrm{pH}$ range when methanol is added to its aqueous solution.
\end{abstract}

KEY WORDS Poly $(S$-benzyloxycarbonylaminoalkyl-homocysteine)s / $\operatorname{Poly}(S$-aminoalkyl-homocysteine)s / Synthesis / $\alpha$-Helix-Coil Transition / Infrared Spectra / Optical Rotatory Dispersion / Circular Dichroism /

In a previous paper, ${ }^{1}$ we synthesized some $\operatorname{poly}(S$-aminoalkyl-L-cysteine $)$ with optically active and inactive groups in its side chain by the NCA method; it has also been reported that such polypeptides can undergo a $\beta$-coil transition. The nonhelix-forming polypeptides are of two types-first, those which are disubstituted by different group from hydrogen on the $\beta$-carbon atom; second, those which have a heteroatom (oxygen or sulfur) attached directly to the $\beta$-carbon atom. ${ }^{2}$ For instance, many kinds of poly $(S$-alkyl cysteine) have been reported to be $\beta$-structures in the solid state and in solution. However, if there is one more methylene group in their side chains, they come to assume the $\alpha$-helix. Furthermore, poly(L-methionine) ${ }^{3}$ and poly $(S \text {-benzyl-L-homocysteine })^{4}$ form a very stable $\alpha$-helix in solution, but the conformational aspects of these polypeptides in aqueous solution has not been reported because of their insolubility in water.

In this paper,the homologous polypeptides of homocysteine which contain one more methylene group than cysteine and their conformational aspects in organic solvent and in aqueous solution are treated. Poly $(S$-2-benzyloxycarbonylaminoethyl-L-homocysteine) (Z-I), poly(S-3-benzyloxycarbonylaminopropyl-L-homocysteine) (ZII), poly( $S$-L-2-benzyloxycarbonylaminopropyl-Lhomocysteine) (Z-III), poly( $S$-L-2-benzyloxycarbonylaminopropyl-D-homocysteine) (Z-IV), poly $(S$ 2-aminoethyl-L-homocysteine) (I), poly $(S$-3-aminopropyl-L-homocysteine) (II), $\operatorname{poly}(S$-L-2-aminopropyl-L-homocysteine) (III), and $\operatorname{poly}(S$-L-2aminopropyl-D-homocysteine) (IV) were synthesized. The forms of the poly $(S$-aminoalkylhomocysteine)s and their benzyloxycarbonyl derivatives are shown as follows: 
$\operatorname{Poly}(S$-aminoalkyl-homocysteine)s
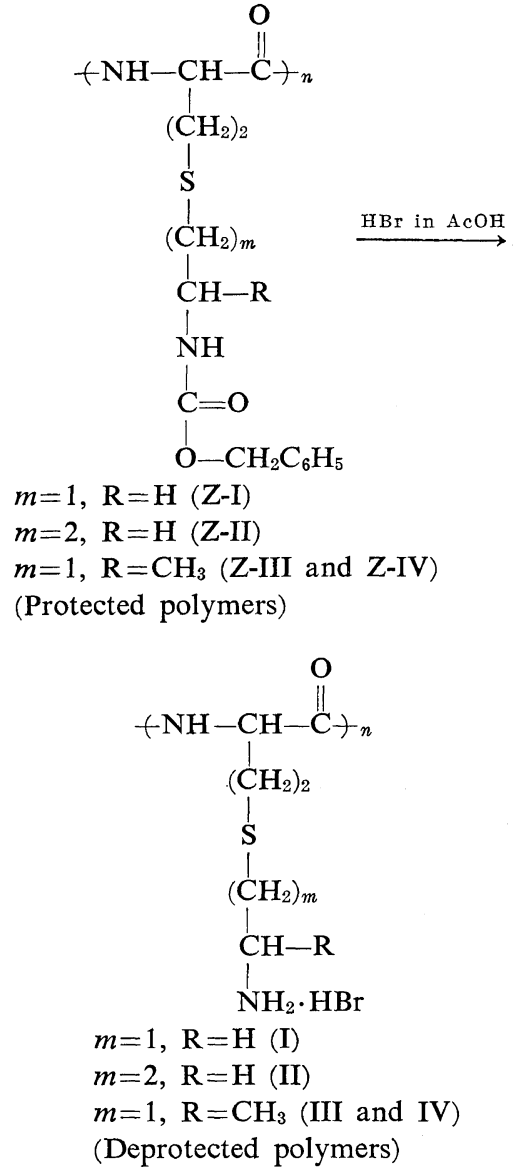

The secondary structures of these polymers were studied in order to investigate the effect of the contribution from the chain length of the alkyl groups and the optically active side chain groups to the polypeptide structure by means of the ORD, CD, and IR spectra in the solid state and in solution.

\section{EXPERIMENTAL}

\section{Materials}

The physical and analytical data of these materials are shown in Tables I and II.

$S$-Z-Benzyloxycarbonylaminoalkyl-homocysteines. $S$ - 2 - Benzyloxycarbonylaminoethyl - L - homocysteine, $S$-3-benzyloxycarbonylaminopropyl-L-homocysteine, $S$-2-L-benzyloxycarbonylaminopropylL-homocysteine, and S-2-L-benzyloxycarbonylaminopropyl-D-homocysteine were prepared from the corresponding benzyloxycarbonylaminoalkyl- bromide and L- and D-homocysteine in the same way as that described in a previous report. ${ }^{1}$

Preparation of $\mathrm{N}$-Carboxyamino Acid Anhydrides $(N C A) . \quad$ The $S$-benzyloxycarbonylaminoalkylhomocysteine NCAs were prepared by the usual procedure.

Preparation of Protected Polymers (Z-I, Z-II, $Z$-III, and $Z-I V$ ). The above NCAs were polymerized in dioxane using triethylamine as an initiator $(A / I=100)$.

Preparation of Deprotected Polymers (I, II, III, and $I V)$. The polypeptide hydrobromides were prepared from the protected polymers by the usual procedure, using hydrogen bromide in glacial acetic acid.

\section{Methods}

IR spectra were measured on a JASCO Model DS-301 spectrophotometer at $22^{\circ} \mathrm{C}$. $\mathrm{CD}$ and ORD were measured on a JASCO ORD/UV-5 spectropolarimeter with a $\mathrm{CD}$ attachment at $22^{\circ} \mathrm{C}$. The measurements were performed with $0.1-$ and $1-\mathrm{mm}$ cells from 260 to $210 \mathrm{~nm}$, and with 10 and $50-\mathrm{mm}$ cells for the visible region. The concentration of the samples were in the 0.1 $1.0-\%$ range. $\mathrm{CD}$ and $\mathrm{ORD}$ are expressed by the residual ellipticity, $[\theta]$, and the reduced residual rotation, $\left[\mathrm{m}^{\prime}\right]$, respectively. The amino end-groups were determined by titration of the polymer in dioxane with $\mathrm{HClO}_{4} /$ acetic acid, using crystal violet as the indicator. The viscosities were measured at $25^{\circ} \mathrm{C}$ using an Ubbelohde viscometer.

\section{RESULTS AND DISCUSSION}

\section{Infrared Absorption Spectra}

The protected polymers (Z-I, Z-II, Z-III, and Z-IV) and the deprotected polymers (I, II, III, and IV) show absorption bands characteristic of polypeptides. The absorptions of amide A, amide I, and amide II are listed in Table III. They showed IR characteristic absorption bands at about $3310 \mathrm{~cm}^{-1}$ (Amide A), $1655 \mathrm{~cm}^{-1}$ (Amide I), and $1540 \mathrm{~cm}^{-1}$ (Amide II). As described below, from the $\left[\mathrm{m}^{\prime}\right]_{233}$ and $b_{0}$ values in the ORD studies of these polymers, we may assume that these polypeptides have the $\alpha$-helix conformation in the solid state.

ORD and $C D$ of Protected Polymers

The ORD and CD spectra of Z-I, Z-III, and 
Table I. The physical properties and elemental analysis of monomers

\begin{tabular}{|c|c|c|c|c|c|c|c|c|c|c|}
\hline \multirow{2}{*}{ Samplea } & \multirow{2}{*}{$\begin{array}{l}\text { Yield, } \\
\%\end{array}$} & \multirow{2}{*}{$\underset{{ }^{\circ} \mathrm{C}}{\mathrm{mp}}$} & \multirow{2}{*}[\alpha]{$_{\mathrm{D}}^{22 \mathrm{~b}}$} & \multirow{2}{*}{$\begin{array}{l}\text { Molecular } \\
\text { formula }\end{array}$} & \multicolumn{3}{|c|}{ Calcd } & \multicolumn{3}{|c|}{ Found } \\
\hline & & & & & $\mathrm{C}, \%$ & $\mathrm{H}, \%$ & $\mathrm{~N}, \%$ & $\overline{C,} \%$ & $\mathrm{H}, \%$ & $\mathrm{~N}, \%$ \\
\hline$S$-2-Z-Aminoethyl-L-homoCys & 56.9 & 228 & 9.0 & $\mathrm{C}_{14} \mathrm{H}_{20} \mathrm{~N}_{2} \mathrm{O}_{4} \mathrm{~S}$ & 53.83 & 6.45 & 8.97 & 53.51 & 6.33 & 8.68 \\
\hline$S$-3-Z-Aminopropyl-L-homoCys & 82.0 & 214 & 8.9 & $\mathrm{C}_{15} \mathrm{H}_{22} \mathrm{~N}_{2} \mathrm{O}_{4} \mathrm{~S}$ & 55.20 & 6.79 & 8.58 & 55.10 & 6.62 & 8.42 \\
\hline$S$-L-2-Z-Aminopropyl-L-homoCys & 60.2 & $215-217$ & 21.6 & $\mathrm{C}_{15} \mathrm{H}_{22} \mathrm{~N}_{2} \mathrm{O}_{4} \mathrm{~S}$ & 55.20 & 6.79 & 8.58 & 55.08 & 6.73 & 8.56 \\
\hline S-L-2-Z-Aminopropyl-D-homoCys & 72.6 & $215-216.5$ & 19.7 & $\mathrm{C}_{15} \mathrm{H}_{22} \mathrm{~N}_{2} \mathrm{O}_{4} \mathrm{~S}$ & 55.20 & 6.79 & 8.58 & 55.13 & 6.69 & 8.60 \\
\hline$S$-2-Z-Aminoethyl-L-homoCys NCA & 99.3 & Oil & - & $\mathrm{C}_{15} \mathrm{H}_{18} \mathrm{~N}_{2} \mathrm{O}_{5} \mathrm{~S}$ & 53.24 & 5.36 & 8.28 & - & - & - \\
\hline$S$-3-Z-Aminopropyl-L-homoCys NCA & 87.4 & 54 & - & $\mathrm{C}_{16} \mathrm{H}_{20} \mathrm{~N}_{2} \mathrm{O}_{5} \mathrm{~S}$ & 54.53 & 5.72 & 7.95 & 54.88 & 5.69 & 7.95 \\
\hline$S$-L-2-Z-Aminopropyl-L-homoCys NCA & 99.5 & Oil & - & $\mathrm{C}_{16} \mathrm{H}_{20} \mathrm{~N}_{2} \mathrm{O}_{5} \mathrm{~S}$ & 54.53 & 5.72 & 7.95 & - & - & - \\
\hline$S$-L-2-Z-Aminopropyl-D-homoCys NCA & 99.8 & Oil & - & $\mathrm{C}_{16} \mathrm{H}_{20} \mathrm{~N}_{2} \mathrm{O}_{5} \mathrm{~S}$ & 54.53 & 5.72 & 7.95 & - & - & - \\
\hline
\end{tabular}

a $\mathrm{Z}$ represents benzyloxycarbonyl.

${ }^{b}$ In acetic acid.

Table II. The physical properties and elemental analysis of polymers

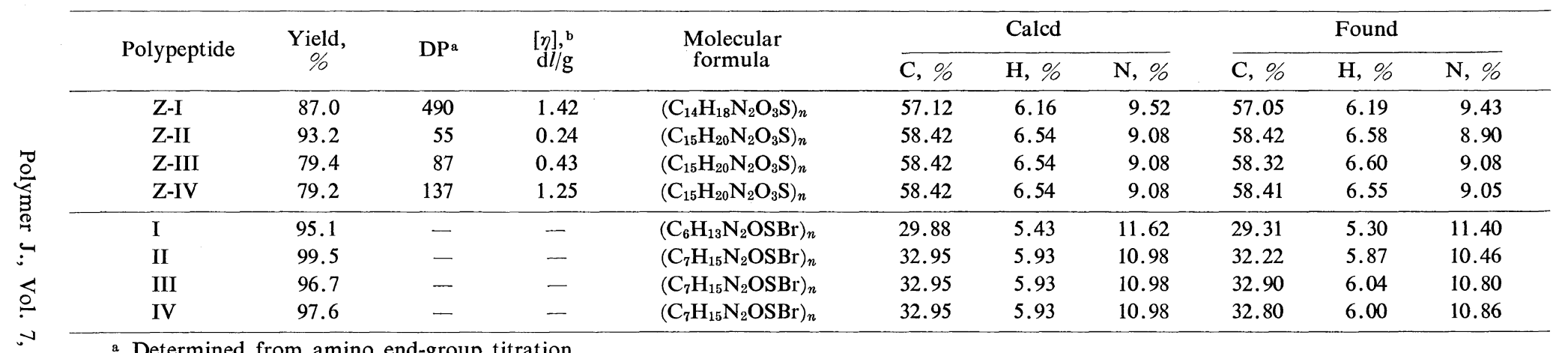

${ }^{a}$ Determined from amino end-group titration.

b In dichloroacetic acid at $25^{\circ} \mathrm{C}$. 
$\operatorname{Poly}(S$-aminoalkyl-homocysteine)s

Table III. Characteristic absorption bands of polypeptides (KBr disks)

\begin{tabular}{|c|c|c|c|c|c|c|c|c|}
\hline \multirow{2}{*}{ Assignment } & \multicolumn{8}{|c|}{ Wave number, $\mathrm{cm}^{-1}$ a } \\
\hline & Z-I & Z-II & Z-III & Z-IV & I & II & III & IV \\
\hline Amide A & 3310 (vs) & 3310 (vs) & 3310 (vs) & 3307 (vs) & 3310 (vs) & 3312 (vs) & 3292 (vs) & 3292 (vs) \\
\hline Amide I & 1656 (vs) & 1655 (vs) & 1660 (vs) & 1658 (vs) & 1655 (vs) & 1659 (vs) & 1650 (vs) & 1650 (vs) \\
\hline Amide II & $1540(\mathrm{~s})$ & $1540(\mathrm{~s})$ & $1547(\mathrm{~s})$ & $1548(s)$ & $1537(s)$ & $1542(\mathrm{~s})$ & $1553(\mathrm{~s})$ & $1545(\mathrm{~s})$ \\
\hline
\end{tabular}

a vs, very strong; s, strong.

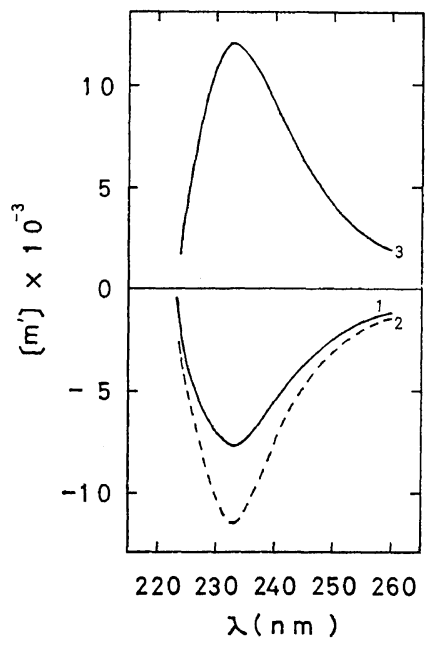

Figure 1. ORD of the protected polymers in chloroform at $22^{\circ} \mathrm{C}$ : $1, \mathrm{Z}$-I; 2, Z-III; 3, Z-IV.

Z-IV in chloroform are shown in Figures 1 and 2. Z-II gave approximately the same behavior as that of Z-I. The protected polymers exhibit a trough (or peak) at $233 \mathrm{~nm}$ with $\left[\mathrm{m}^{\prime}\right]_{233}=$ $-7,700-11,450 \mathrm{deg} \mathrm{cm}^{2} / \mathrm{dmol}(+11,870)$, and a negative (or positive) dichroism band near 229 $\mathrm{nm}$, with $[\theta]_{229}=-16,500-19,500 \mathrm{deg} \mathrm{\textrm {cm } ^ { 2 }} / \mathrm{dmol}$ $(+19,160)$ in chloroform. These ORD and CD behaviors are essentially identical with those of the right-handed (or left-handed) $\alpha$-helix of the other polypeptides. The dichroism band at 229 $n m$ can be assigned to the red shifted $n-\pi^{*}$

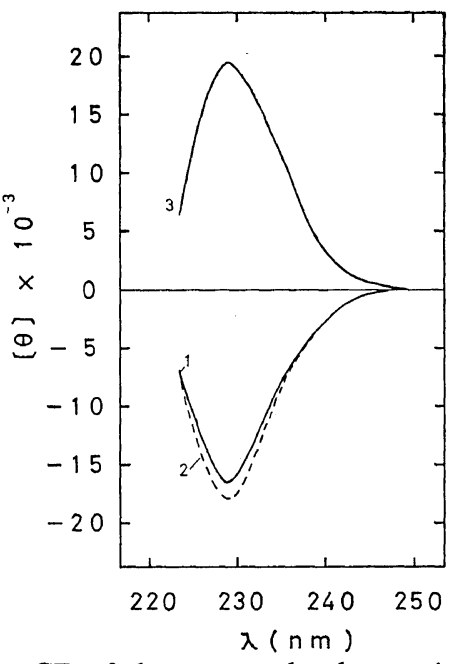

Figure 2. $\mathrm{CD}$ of the protected polymers in chloroform at $22^{\circ} \mathrm{C}$ : Symbols are the same as in Figure 1 .

peptide electronic transition of polypeptide due to the interaction between $S$ atom and $Z$-protected group. The values of $\left[\mathrm{m}^{\prime}\right]_{233},[\theta]_{229}$, and $b_{0}$ are listed in Table IV. From Table IV it can be seen that in the case of Z-III and Z-IV with optically active side chains, each value appeared larger than those of Z-I and Z-II. This may be caused by the influence of the optically active side chain. The results of the helix-coil transition in the protected polymers examined from the $b_{0}$ value in a chloroform-DCA mixture are illustrated in Figure 3. Figure 3 shows

Table IV. $b_{0},\left[m^{\prime}\right]_{233}$, and $[\theta]_{229}$ values of Z-protected polypeptides at $22^{\circ} \mathrm{C}$

\begin{tabular}{|c|c|c|c|c|}
\hline \multirow[b]{2}{*}{ Polypeptide } & \multicolumn{3}{|c|}{ In chloroform } & \multirow{2}{*}{$\begin{array}{c}\text { In dichloroacetic acid } \\
b_{0}, \\
\operatorname{deg} \mathrm{cm}^{2} / \mathrm{dmol}\end{array}$} \\
\hline & $b_{0}$ & $\begin{array}{c}{\left[m^{\prime}\right]_{233},} \\
\operatorname{deg~} \mathrm{cm}^{2} / \mathrm{dmol}\end{array}$ & {$[\theta]_{229}$} & \\
\hline Z-I & -580 & $-7,700$ & $-16,500$ & -50 \\
\hline Z-II & -575 & $-9,800$ & $-19,500$ & 0 \\
\hline Z-III & -600 & $-11,450$ & $-17,300$ & 0 \\
\hline Z-IV & 670 & 11,870 & 19,200 & 50 \\
\hline
\end{tabular}


that the helix-coil transition of the aminoethyl derivative Z-I takes place at $80-\%$ DCA, while this transition of the aminopropyl derivatives Z-II, Z-III, and Z-IV occurs at 60-\% DCA. These results may be assumed to indicate either that the polypeptides arise from the difference of a methylene group in the side chain or that the molecular weight of the polypeptide is much smaller than that of the Z-I. The helix stabilities of these polymers are higher than that of $\operatorname{poly}\left(N^{\varepsilon}\right.$-benzyloxycarbonyl-L-lysine $),{ }^{5}$ while they are lower than that of poly(L-methionine). ${ }^{2}$ This could be interpreted as due to the situation that the introduction of the bulky side chain

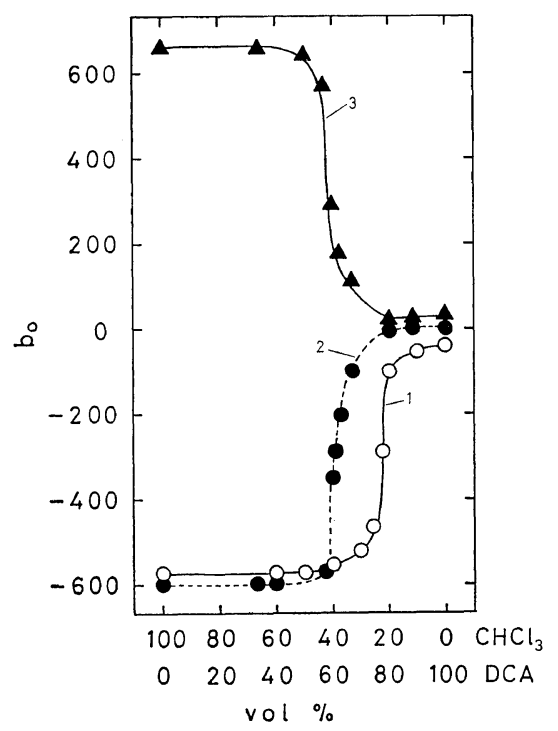

Figure 3. Helix - coil transition of the protected polymers in mixed solvents of chloroform and dichloroacetic acid (DCA) at $22^{\circ} \mathrm{C}$ : 1 , Z-I; 2, Z-III; 3, Z-IV. made the helix unstable.

\section{$O R D$ and $C D$ of Deprotected Polymers}

The ORD and CD measurements of the deprotected polymers (I, II, III, and IV) were carried out by means of changing $\mathrm{pH}$ in water and in $1: 1$ water-methanol. The ORD curves of $\mathrm{I}$ at various $\mathrm{pH}$ in aqueous solution are shown in Figure 4. In the $\mathrm{pH}$ below 7.4, the polypeptide is in a random coil structure which has a $238 \mathrm{~nm}$ trough. However, when the $\mathrm{pH}$ is increased above 7.5 , a remarkable change in the ORD spectrum is observed and the trough at $238 \mathrm{~nm}$ shifts to $233 \mathrm{~nm}$. In the $\mathrm{pH}$ above 8.83 , the polypeptide exhibits a trough at $233 \mathrm{~nm}$ with

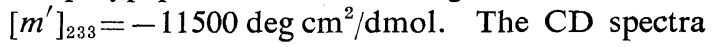
correspond well with that observed in the ORD, showing dichroism bands at $222 \mathrm{~nm}$ reaching

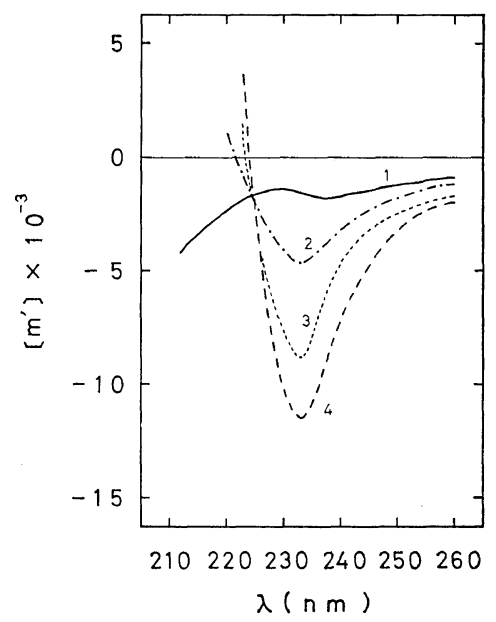

Figure 4. ORD of poly( $S$-2-aminoethyl-L-homocysteine) (I) as a function of $\mathrm{pH}$ in aqueous media at $22^{\circ} \mathrm{C}: 1, \mathrm{pH} 6.02 ; 2, \mathrm{pH} 7.73 ; 3, \mathrm{pH} 8.13 ; 4$, $\mathrm{pH} 8.83$.

Table V. Values of $\left[m^{\prime}\right]_{233}$ and $[\theta]_{222}$ for deprotected polypeptides at $22^{\circ} \mathrm{C}$

\begin{tabular}{|c|c|c|c|c|c|c|c|c|}
\hline \multirow{2}{*}{$\begin{array}{c}\text { Optical } \\
\text { activity }^{\mathrm{a}}\end{array}$} & \multicolumn{2}{|c|}{ I } & \multicolumn{2}{|c|}{ II } & \multicolumn{2}{|c|}{ III } & \multicolumn{2}{|c|}{ IV } \\
\hline & $\mathrm{pH} 5.0$ & 9.0 & 5.0 & 9.0 & 5.0 & 9.0 & 5.0 & 9.0 \\
\hline \multicolumn{9}{|c|}{ In water } \\
\hline$\left[m^{\prime}\right]_{233}$ & $-1,700$ & $-11,500$ & $-1,500$ & $-7,300$ & -550 & $-12,700$ & 2,250 & 14,900 \\
\hline$[\theta]_{222}$ & 1,640 & $-34,700$ & $-1,200$ & $-22,300$ & 2,750 & $-40,300$ & $-1,800$ & 47,000 \\
\hline \multicolumn{9}{|c|}{ In $1: 1$ water-methanol $(\mathrm{v} / \mathrm{v})$} \\
\hline$\left[m^{\prime}\right]_{233}$ & $-4,600$ & $-11,750$ & $-6,700$ & $-8,500$ & $-2,000$ & $-12,700$ & 3,400 & 13,900 \\
\hline$[\theta]_{222}$ & $-5,500$ & $-37,000$ & $-21,200$ & $-29,300$ & $-3,000$ & $-41,300$ & 6,200 & 48,000 \\
\hline
\end{tabular}

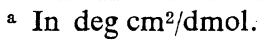


$[\theta]_{222}=-33000$ at $\mathrm{pH}$ above 8.83 . The polymers II, III, and IV show nearly the same behavior. In Table $\mathrm{V}$ the value of the $\left[\mathrm{m}^{\prime}\right]_{233}$ and $[\theta]_{222}$ measured for each polymer at about $\mathrm{pH} 5.0$ and 9.0 in water and in $1: 1$ water-methanol are listed. The magnitudes of the $\left[\mathrm{m}^{\prime}\right]_{233}$ and $[\theta]_{222}$ of the polymers III and IV are much larger than those of the polymers I and II. When 50-\% (v/v) methanol is added to the solution, the polymer is also able to form the $\alpha$-helix conformation at lower pH. In the case of the polymer II it shows $\left[m^{\prime}\right]_{233}=-6700$ and $[\theta]_{222}=-21200$ at $\mathrm{pH}$ 5 , suggesting nearly $50 \%$ exists as $\alpha$-helix. The magnitude of the $[\theta]_{222}$ of the polymers III and IV in water and in $1: 1$ water-methanol is plotted in Figure 5. It can be recognized that the helix-coil transition occurs at lower $\mathrm{pH}$ and

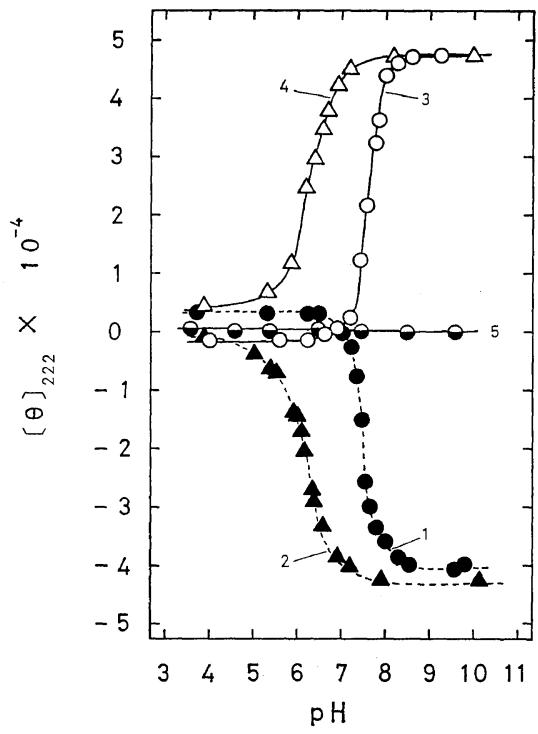

Figure 5. Helix-coil transition of the deprotected polymers in aqueous media at $22^{\circ} \mathrm{C}$ : 1 , III (in $\mathrm{H}_{2} \mathrm{O}$ ); 2 , III (in $1: 1 \mathrm{CH}_{3} \mathrm{OH}-\mathrm{H}_{2} \mathrm{O}$ ); 3 , IV (in $\mathrm{H}_{2} \mathrm{O}$ ); 4, IV (in $1: 1 \mathrm{CH}_{3} \mathrm{OH}-\mathrm{H}_{2} \mathrm{O}$ ); 5 , equal proportions of III and IV (in $\mathrm{H}_{2} \mathrm{O}$ ). that they enhance the helix stability by addition of methanol. The polymers I and II were observed to behave similarly. The midpoint of the transition of the polymer $\mathrm{I}$ is at the $\mathrm{pH}$ 7.8 in water and at $\mathrm{pH} 6.0$ in $1: 1$ watermethanol, respectively. In the polymer II, these points are at the $\mathrm{pH} 8.3$ and at the $\mathrm{pH} 7.5$, and in the case of III and IV they are observed at $\mathrm{pH} 7.6$ and at $\mathrm{pH}$ 6.2. The helix-coil transition of the polymer occurs at lower $\mathrm{pH}$ than in water owing to the addition of methanol in every case. This indicates that the stability of the segments of the alkyl groups in the side chain would occur as a result of the dehydration caused by the addition of methanol to the solution. The $\left[\mathrm{m}^{\prime}\right]_{233}$ values of the blend of equal proportions of the polymers III and IV in aqueous solution are plotted in Figure 5. As expected, they appear in the middle of the two polymers.

As described above, the ORD and CD results suggest that the magnitude of the $n-\pi^{*}$ transition of the polymers III and IV with the optically active side chain is somewhat different from that of the polymer II with the optically inactive side chain. However, no clear difference appeared in the stability of the helix or in the magnitude of $n-\pi^{*}$ transitional absorption of the polypeptide.

\section{REFERENCES}

1. T. Hayakawa, Y. Kondo, and Y. Murakami, Polymer J., 6, 424 (1974).

2. E. R. Blout, "Polyamino Acids, Polypeptides and Proteins," M. A. Stahman Ed., The University of Wisconsin Press, Wisconsin, 1962, p 275.

3. S. M. Bloom, G. D. Fasman, C. deLozé, and E. R. Blout, J. Amer. Chem. Soc., 84, 458 (1962).

4. T. Hayakawa, et al., unpublished data.

5. G. D. Fasman, "Poly $(\alpha$-amino acids)," G. D. Fasman Ed., Marcel Dekker Inc., New York, N. Y., 1967, p 499. 